\title{
Análise do uso de grãos de areia de britagem de orgem granítica na produção de
}

\section{argamassas de revestimento}

\author{
Analysis of the use of grains from crushing sand of granitic origin in the production of coating
}

mortars

Análisis del uso de granos de arena de trituración de origen granítico en la producción de morteros de revestimiento

Recebido: 26/03/2021 | Revisado: 31/03/2021 | Aceito: 05/04/2021 | Publicado: 15/04/2021

\author{
Carina Beleia Antunes \\ ORCID: https://orcid.org/0000 -0002-6321-2540 \\ Universidade Federal de Pelotas, Brasil \\ E-mail: carinabeleia.cb@gmail.com \\ Margarete Regina Freitas Gonçalves \\ ORCID: https://orcid.org/0000 0001-6834-8546 \\ Universidade Federal de Pelotas, Brasil \\ E-mail: margareterfg@gmail.com
}

\begin{abstract}
Resumo
A construção civil é responsável por elevado índice de impacto ambiental causado pelo consumo não consciente de matéria-prima. Dentre os recursos naturais mais esgotados estão as areias de rios que vem sendo substituídas por areias provenientes de britagem de rocha. O uso desse tipo de areia com procedimentos adequados pode ser uma alternativa viável para a substituição da areia natural na produção de argamassa de revestimento. Em referenciais bibliográficos são encontradas informações envolvendo análises sobre o uso de areia de britagem de rochas calcárias e basálticas e poucas envolvendo areias de rochas graníticas, resíduo este produzido em grande escala na região Sul do Rio Grande do Sul, em especial em regiões de extração de granito como a cidade do Capão do Leão. Considerando tais fatos, no presente trabalho realizou-se a análise da utilização de uma areia de britagem de origem granítica em substituição parcial $(50 \%)$ e total (100\%) da areia natural de uma argamassa de revestimento, produzida com o traço 1:1:6 (cimento, cal e areia, respectivamente). Na análise buscou-se verificar a influência das características dos grãos de areia granítica nas propriedades de argamassas de revestimentos. As areias utilizadas foram analisadas quanto a granulometria, massa específica, massa unitária, mineralogia, absorção e forma do grão. E, nas argamassas com areia natural e com areia granítica analisou-se no estado fresco o índice de consistência e no estado endurecido a absorção por capilaridade, a resistência à compressão axial e a resistência à tração na flexão a três pontos.

Palavras-chave: Areia de britagem granítica; Forma dos grãos; Argamassa de revestimentos; Permeabilidade; Resistência mecânica.
\end{abstract}

\begin{abstract}
Civil construction is responsible for a high rate of environmental impact caused by unaware consumption of raw materials. Among the most depleted natural resources are river sands that are being replaced by sand from rock crushing. The use of this type of sand with adequate procedures can be a viable alternative for the substitution of natural sand in the production of coating mortar. In bibliographical references, information involving analyses about the use of crushed sand from limestone and basalt rocks are found, and few involving sand from granite rocks, a residue produced in large scale in the southern region of Rio Grande do Sul, especially in regions of granite extraction, such as the city of Capão do Leão. Considering these facts, in the present work, an analysis of the use of a crushed sand of granite origin in partial $(50 \%)$ and total $(100 \%)$ substitution of the natural sand of a coating mortar, produced with the mix 1:1:6 (cement, lime and sand, respectively), was carried out. The analysis aimed at verifying the influence of the granite sand grain characteristics on the coating mortar properties. The sands used were analyzed for grain size, specific mass, unit mass, mineralogy, absorption and grain shape. The mortars with natural sand and with granite sand were analyzed in the fresh state for the consistency index, and in the hardened state for capillary absorption, axial compressive strength, and three-point flexural tensile strength.
\end{abstract}

Keywords: Granite crushed sand; Grain shape; Mortar coatings; Permeability; Mechanical strength.

\section{Resumen}

La construcción civil es responsable de un alto índice de impacto ambiental causado por el consumo inconsciente de materias primas. Entre los recursos naturales más agotados están las arenas de los ríos, que están siendo sustituidas 
por arena procedente de la trituración de rocas. El uso de este tipo de arena con procedimientos adecuados puede ser una alternativa viable para la sustitución de la arena natural en la producción de mortero de revestimiento. En las referencias bibliográficas, existen informaciones que involucran análisis sobre el uso de arena triturada de rocas calcáreas y basálticas y pocas que involucran arena de rocas graníticas, residuo producido en gran escala en la región sur de Rio Grande do Sul, especialmente en regiones de extracción de granito como la ciudad de Capão do Leão. Teniendo en cuenta estos hechos, en el presente trabajo se realizó el análisis del uso de una arena triturada de origen granítico en sustitución parcial $(50 \%)$ y total $(100 \%)$ de la arena natural de un mortero de revestimiento, producido con la mezcla 1:1:6 (cemento, cal y arena, respectivamente). El análisis tenía como objetivo verificar la influencia de las características del grano de la arena de granito en las propiedades del revestimiento del mortero. Las arenas utilizadas fueron analizadas en cuanto a tamaño de grano, masa específica, masa unitaria, mineralogía, absorción y forma del grano. Los morteros con arena natural y arena de granito se analizaron en estado fresco para el índice de consistencia y en estado endurecido para la absorción de la capilaridad, la resistencia a la compresión axial y la resistencia a la tracción por flexión en tres puntos.

Palabras clave: Arena granítica triturada; Forma del grano; Revestimientos de mortero; Permeabilidad; Resistencia mecánica.

\section{Introdução}

A construção civil é o ramo de atividade que mais consome recursos não renováveis em todo o planeta. No entanto, também é um setor com uma vasta gama de possibilidades de incorporar rejeitos gerados de diversas atividades e assim minimizar seu próprio impacto.

Uma forma de minimizar tal situação é associar a problemática da redução do impacto ambiental com a elevada demanda na necessidade de produtos e tecnologias construtivas, que garantam um melhor desempenho e maior durabilidade através de pesquisas de inovação tecnológica para o ramo da construção civil.

Nesse contexto se insere a importância de obtenção de fontes alternativas em substituição a areia natural, tendo em vista as consequências de sua exaustiva exploração, com consequente agressão aos leitos dos rios e de suas margens, bem como a redução das áreas de exploração devido à restrição dos órgãos ambientais diante da liberação de novas licenças de operação para esse tipo de recurso natural.

Dentre diversas possibilidades, cada vez mais tem crescido o interesse no uso de agregados reciclados, principalmente, para a produção de concretos e argamassas. O uso de areia de britagem, por exemplo, em substituição a areia natural é uma alternativa que vem despertando grande interesse.

Pesquisas recentes feitas por (Kazmierczak, Rosa \& Arnold, 2016), que realizaram um estudo analisando a influência da adição de filler de areia de britagem de origem basáltica nas argamassas de revestimento, e por (Baderina, 2013), que analisaram a substituição de areia natural por areia de britagem de calcário em argamassas de revestimento e sua exposição em soluções químicas (cal e ácido clorídrico), mostraram a viabilidade das substituições.

Outro trabalho que mostra a possibilidade do emprego da areia de britagem é o de (Cepuritis ,2017) que, ao analisarem a influência da forma dos grãos finos do agregado artificial proveniente de trituração em um britador do tipo VSI, perceberam a influência destes nas propriedades de resistência à flexão e à compressão axial em argamassas.

Na pesquisa de (Santos, Veiga, Silva \& Brito, 2020), eles analisaram a influência dos agregados miúdos nas argamassas, permitindo estabelecer uma relação quanto ao desempenho, distribuição granulométrica e porosidade. No trabalho foram analisados grãos de areia sílica natural, sílica triturada, calcárica, basáltica e granítica.

(Srivastava \& Singh, 2020) analisaram as características física, química, mineralógica e morfológica de diversas alternativas em substituição ao agregado miúdo nas argamassas, dentre elas a areia de rocha britada. Foi feita uma análise crítica das argamassas nos estados fresco e endurecido e, também, sobre a sua durabilidade.

A areia de britagem, assim como outros materiais produzidos nas unidades industriais, é estocada em montes ao ar livre sujeitos às intempéries, podendo gerar impactos ambientais e poluição atmosférica, sendo, por isto, a sua reciclagem uma alternativa ambientalmente interessante. Além disto, ela é um produto não valorizado dentro das empresas que produzem 
agregados britados, sendo muitas vezes mantidos em estoque por não ter uma classificação usual dentro do ramo de comercialização de agregados. Por falta de conhecimento das características das areias britadas, esse material é utilizado em situações sem grandes exigências tecnológicas como a comercialização para uso em aterros.

\section{Metodologia}

Trata-se de uma pesquisa realizada em laboratório seguindo as normas brasileiras para argamassas de revestimento para obter um resultado quantitativo dos materiais analisados.

Para o desenvolvimento da pesquisa foram utilizados como aglomerantes o cimento Portland CP IV-32 (Tabela 1).

Tabela 1 - Características cimento Portland CP IV-32.

\begin{tabular}{|c|c|c|c|}
\hline Características & \multicolumn{2}{|c|}{ Tipo de ensaio } & Resultados \\
\hline \multirow{8}{*}{$\begin{array}{l}\text { Físicas e } \\
\text { Mecânicas }\end{array}$} & \multirow{2}{*}{ Finura $(\%)$} & $\# 200$ & 0,29 \\
\hline & & \#325 & 1,31 \\
\hline & \multicolumn{2}{|l|}{ Blaine $\left(\mathrm{cm}^{2} / \mathrm{g}\right)$} & 4998 \\
\hline & \multirow{2}{*}{ Tempo de pega (min) } & Início de pega & 350 \\
\hline & & Fim de pega & 445 \\
\hline & \multirow{3}{*}{$\begin{array}{l}\text { Resistência à compressão } \\
(\mathrm{MPa})\end{array}$} & 3 dias & 21,30 \\
\hline & & 7 dias & 24,90 \\
\hline & & 28 dias & 39,10 \\
\hline \multirow{4}{*}{ Químicas } & \multicolumn{2}{|l|}{ Resíduo insolúvel (\%) } & 40,60 \\
\hline & \multicolumn{2}{|l|}{ Perda ao fogo $(\%)$} & 2,00 \\
\hline & \multicolumn{2}{|l|}{$\mathrm{SO} 3(\%)$} & 2,00 \\
\hline & \multicolumn{2}{|l|}{$\mathrm{MgO}(\%)$} & 4,70 \\
\hline
\end{tabular}

Fonte: Intercement, Candiota, RS, Brasil (2019).

Também foi utilizado como aglomerante a cal hidratada (Tabela 2), cujas características foram fornecidas pelos fabricantes.

Tabela 2 - Características cal hidratada.

\begin{tabular}{l|l|l}
\hline \multicolumn{1}{c|}{ Química } & \multicolumn{2}{c}{ Análise (\%) } \\
\hline Óxidos totais & \multicolumn{2}{|c}{$62,00 \%$} \\
\hline Óxidos não hidratados & \multicolumn{2}{|c}{$10,45 \%$} \\
\hline $\mathrm{CaO}$ & \multicolumn{2}{|c}{$31,02 \%$} \\
\hline $\mathrm{MgO}$ & \multicolumn{2}{|c}{$20,49 \%$} \\
\hline \multicolumn{1}{c|}{ Física } & \multicolumn{2}{|c}{$38,94 \%$} \\
\hline $\mathrm{RI}$ - resíduos insolúveis & \multicolumn{2}{|c}{$11,86 \%$} \\
\hline $\mathrm{PF}$ - perda ao fogo & \multicolumn{2}{|c}{ Análise (\%) } \\
\cline { 2 - 3 } & Limites & Análises \\
\hline Peneira 0,6mm & $\leq 0,5 \%$ & $0 \%$ \\
\hline Peneira $0,075 \mathrm{~mm}$ & $\leq 15 \%$ & $12,89 \%$ \\
\hline
\end{tabular}

Fonte: Dagoberto Barcellos, Caçapava do Sul, RS, Brasil (2019). 
Os agregados miúdos utilizados no trabalho foram uma areia natural comercial e uma areia de britagem de origem granítica, proveniente de uma pedreira localizada na cidade do Capão do Leão, RS, que foi extraída por meio de moagem em um britador do tipo mandíbula.

A areia natural apresenta características físicas conforme Tabela 3.

Tabela 3 - Caracterização física da areia natural.

\begin{tabular}{|c|c|c|}
\hline \multirow{2}{*}{ Composição granulométrica/ NBR NM 248:2003 } & Ø máx (mm) & 4,75 \\
\hline & Módulo de Finura & 2,84 \\
\hline \multicolumn{2}{|l|}{ Massa específica $\left(\mathrm{g} / \mathrm{cm}^{3}\right) /$ NBR NM 52:2009 e NBR NM } & 2,62 \\
\hline Massa unitária solta $\left(\mathrm{g} / \mathrm{cm}^{3}\right)$ / NBR NM 45:2006 & & 1,55 \\
\hline
\end{tabular}

Fonte: Autores.

A análise mineralógica apresenta características conforme Figura 1 em que a mesma apresentou-se composta em maior proporção por quartzo e, também, foram encontradas quantidades de feldspato.

Figura 1 - Análise mineralógica da areia natural, por difração de raio-X (DRX).

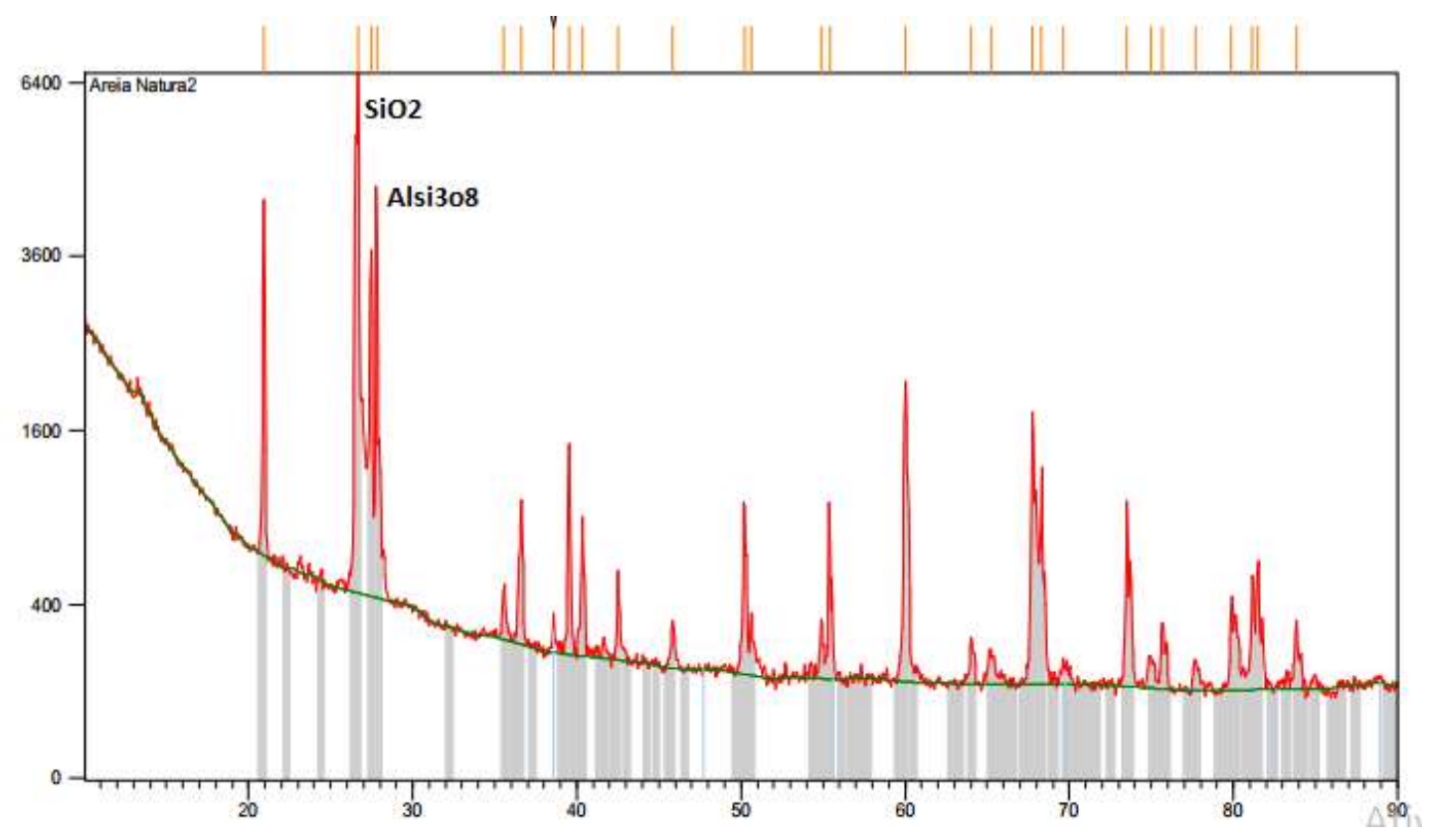

Fonte: Autores.

A areia de britagem de origem granítica apresenta características físicas conforme Tabela 4 e mineralógicas conforme Figura 2 em que a mesma apresentou-se composta em maior proporção por quartzo e fluoreto de cálcio. 
Research, Society and Development, v. 10, n. 4, e39110414312, 2021

(CC BY 4.0) | ISSN 2525-3409 | DOI: http://dx.doi.org/10.33448/rsd-v10i4.14312

Tabela 4 - Caracterização física da areia de britagem de orígem granítica.

\begin{tabular}{|c|c|c|}
\hline \multirow{2}{*}{ Composição granulométrica/ NBR NM 248:2003 } & $\varnothing$ máx $(\mathrm{mm})$ & 4,75 \\
\hline & Módulo de Finura & 2,83 \\
\hline \multicolumn{2}{|c|}{ Massa específica $\left(\mathrm{g} / \mathrm{cm}^{3}\right)$ / NBR NM 52:2009 e NBR NM } & 2,159 \\
\hline \multicolumn{2}{|c|}{ Massa unitária solta $\left(\mathrm{g} / \mathrm{cm}^{3}\right) /$ NBR NM 45:2006 } & 1,76 \\
\hline
\end{tabular}

Fonte: Autores.

Figura 2 - Análise mineralógica da areia granítica, por difração de raio-X (DRX).

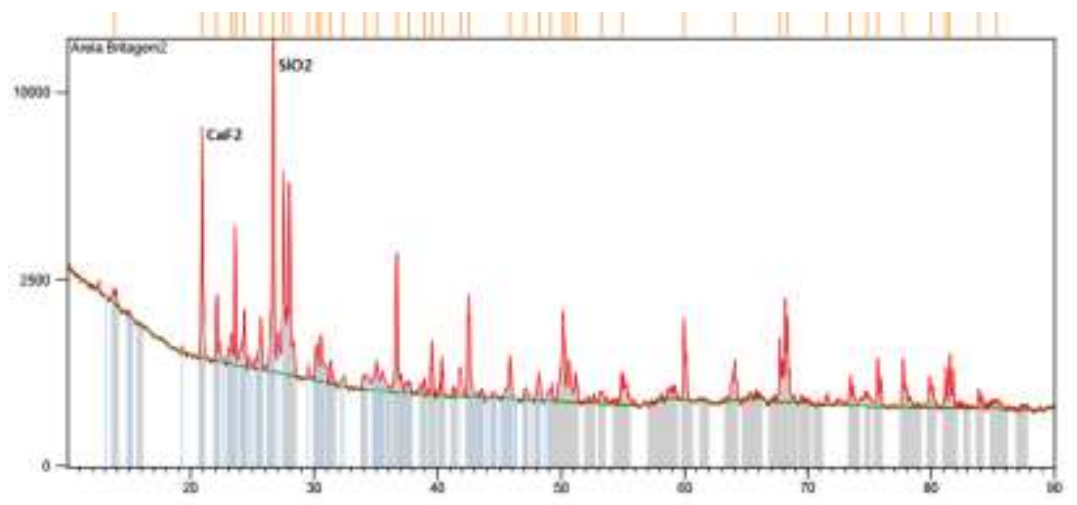

Fonte: Autores.

A análise das Figuras 3 e 4 mostrou que existe efetiva diferença no formato dos grãos de areia, sendo o grão da areia natural mais arredondado e o grão de areia de britagem mais anguloso. Resultados similares já haviam sido identificados por (Karzmierczac, Rosa \& Arnold, 2016) e (Tokarski, 2017) em argamassas com areia de britagem calcária e basáltica.

No tocante a morfologia da areia granítica, mostra serem os grãos angulosos e terem a superfície irregular, aspectos estes já identificados por (Cordeiro, Alvarenga \& Rocha, 2016) em suas pesquisas com areias calcárias e basálticas.

Figura 3 - Morfologia dos grãos de areia natural retidos na peneira \#4,75.

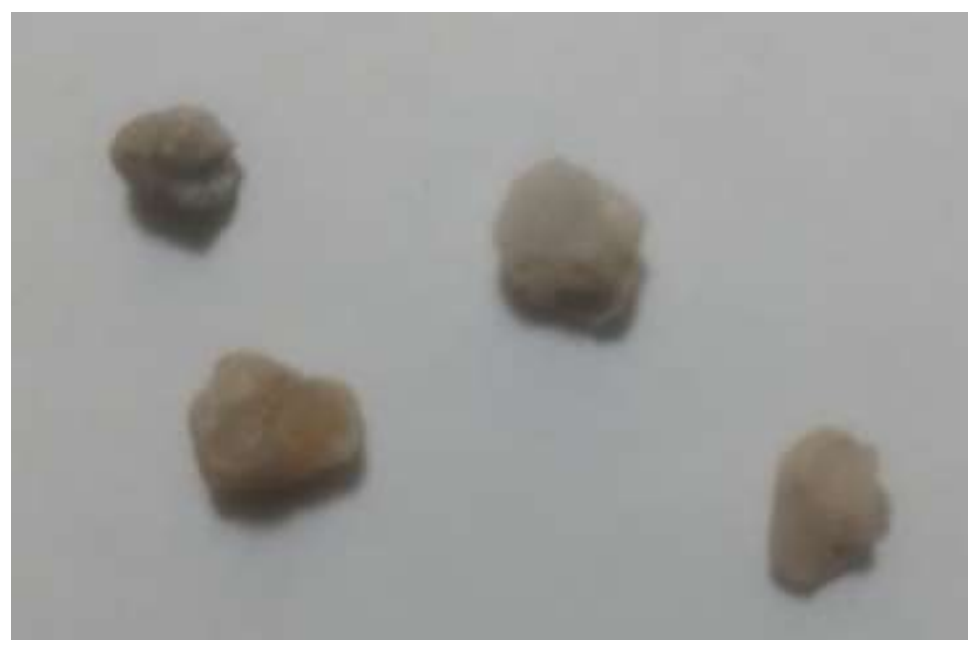

Fonte: Autores. 
Figura 4 - Morfologia dos grãos de areia granítica retidos na peneira \#4,75.

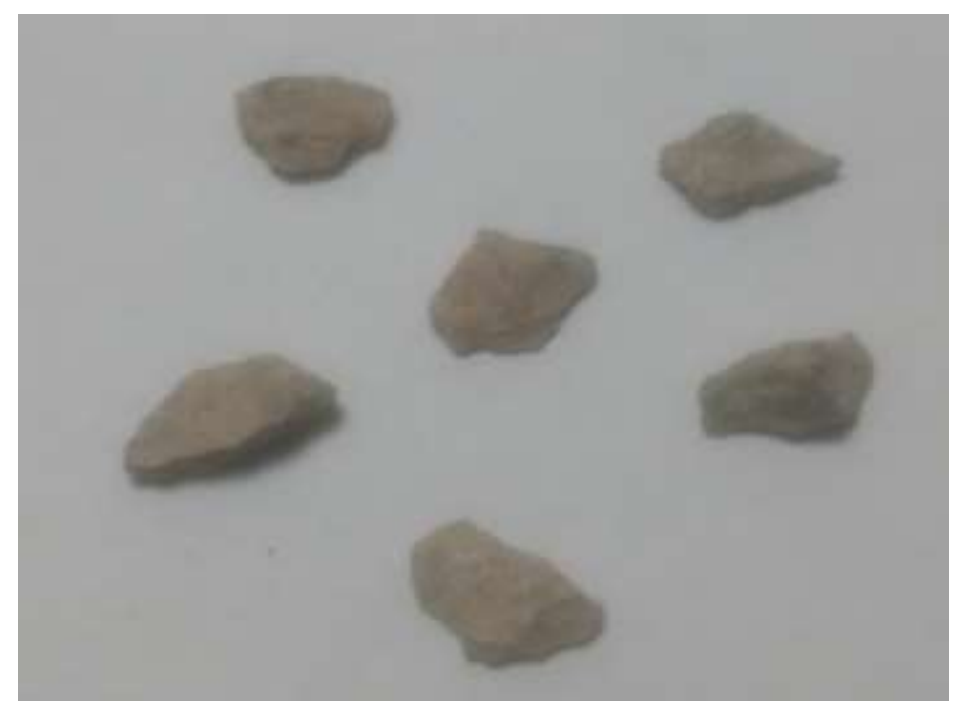

Fonte: Autores.

A análise das curvas granulométricas da Figura 5 mostrou que as areias natural e granítica apresentam distribuição normal, dentro dos limites estabelecidos pela (NBR NM 248 ABNT, 2003). Esta condição resultou na obtenção de propriedades físicas similares entre as areias. Os resultados obtidos foram de extrema importância para a proposta da pesquisa, tendo em vista que este ocorreu com substituição da areia natural pela areia granítica.

Figura 5 - Distribuição granulométrica das areias natural e granítica.
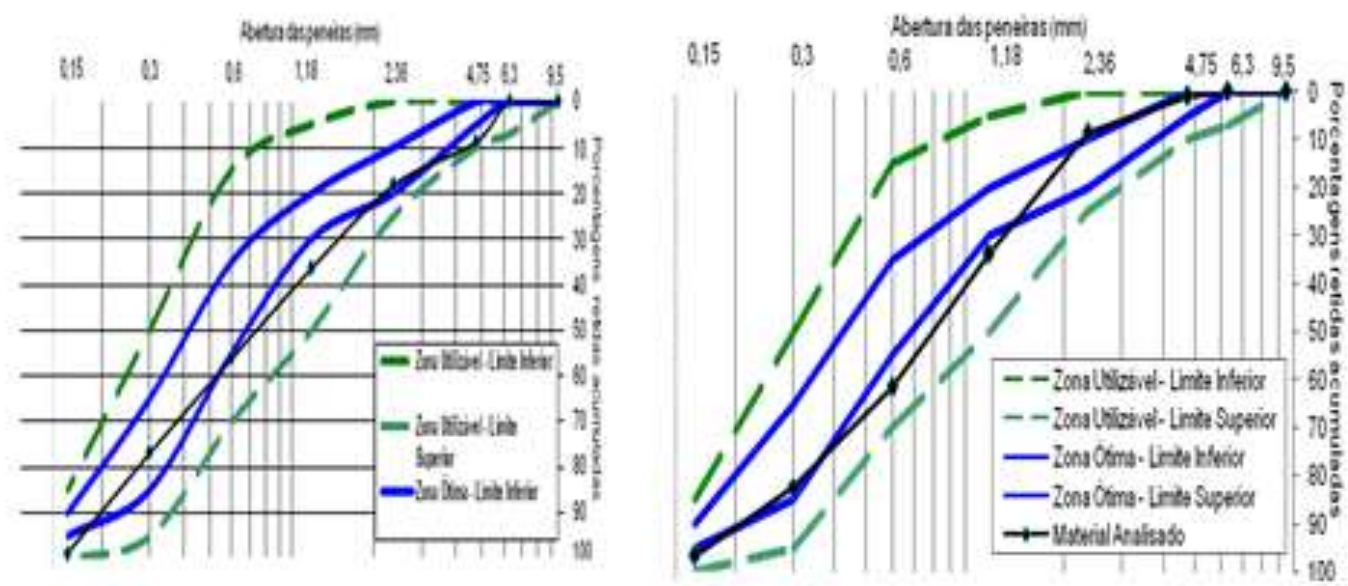

Fonte: Autores.

A análise das Tabelas 5 e 6 mostraram que os grãos de areia granítica apresentam teor de absorção muito superior $(0,72 \%)$ ao identificado nos grãos de areia natural $(0,35 \%)$. Possivelmente, a maior absorção ocorrida é decorrente da presença de grande quantidade de poros na superfície rugosa dos grãos de areia granítica.

Os resultados de absorção de água obtidos para os grãos de areia granítica se assemelham aos encontrados por (Tretin, 2020) quando analisou a absorção dos grãos de areia basáltica. 
Tabela 5 - Teor de absorção de água dos grãos de areia natural.

\begin{tabular}{c|c|c|c}
\hline Amostras & Peso seco $(\mathrm{g})$ & Peso úmido (g) & Absorção de água (\%) \\
\hline 1 & 1016,53 & 1020 & 0,34 \\
\hline 2 & 986,14 & 990 & 0,39 \\
\hline 3 & 998,79 & 1002 & 0,32 \\
\hline \multicolumn{3}{r|}{} \\
\hline
\end{tabular}

Fonte: Autores.

Tabela 6 - Teor de absorção de água dos grãos de areia granítica.

\begin{tabular}{c|c|c|c}
\hline Amostras & Peso seco $(\mathrm{g})$ & Peso úmido $(\mathrm{g})$ & Absorção de água (\%) \\
\hline 1 & 997,66 & 1005 & 0,73 \\
\hline 2 & 992,11 & 999 & 0,69 \\
\hline 3 & 993,5 & 1001 & 0,75 \\
\hline \multicolumn{2}{r}{} \\
\hline
\end{tabular}

Fonte: Autores.

Devido ao melhor desempenho em estudos já realizados, o traço escolhido para o desenvolvimento da pesquisa foi o 1:1:6 (cimento: cal: areia) e com ele foram moldadas três formulações diferentes: uma com areia natural, identificada como o traço referência (REF-AN); outra com substituição de 50\% da areia natural por areia granítica, identificada por 50-AB; e a última com substituição de $100 \%$ da areia natural por areia de britagem de origem granítica, identificada por 100-AB.

O traço foi medido em peso em uma balança de precisão de $0,01 \mathrm{~g}$. A Tabela 7 apresenta as formulações utilizadas.

Tabela 7 - Formulação das argamassas.

\begin{tabular}{c|c|c|c|c}
\hline Formulação & Cimento & Cal & Areia natural & Areia granítica \\
\hline REF-AN & $1 \mathrm{~kg}$ & $1 \mathrm{~kg}$ & $6 \mathrm{~kg}$ & - \\
\hline $50-\mathrm{AB}$ & $1 \mathrm{~kg}$ & $1 \mathrm{~kg}$ & $3 \mathrm{~kg}$ & $3 \mathrm{~kg}$ \\
\hline $100-\mathrm{AB}$ & $1 \mathrm{~kg}$ & $1 \mathrm{~kg}$ & - & $6 \mathrm{Kg}$ \\
\hline
\end{tabular}

Fonte: Autores.

A Tabela 8 apresenta o número total de corpos de prova confeccionados e a distribuição deles por ensaio.

Tabela 8 - Número de corpos de prova.

\begin{tabular}{c|c|c|c|c}
\hline \multirow{2}{*}{ Argamassa } & \multicolumn{1}{|c|}{$\begin{array}{c}\text { Resistência à } \\
\text { compressão axial }\end{array}$} & $\begin{array}{c}\text { Absorção por } \\
\text { capilaridade }\end{array}$ & $\begin{array}{c}\text { Resistência à tração } \\
\text { na flexão }\end{array}$ & \multirow{2}{*}{ Total } \\
\cline { 2 - 4 } & \multicolumn{3}{|c|}{$\mathbf{n}^{\circ}$ corpos de prova } & \multirow{2}{*}{3} \\
\hline TREF-AN & 5 & 5 & 3 & 3 \\
\hline $50-\mathrm{AB}$ & 5 & 5 & 3 & \\
\hline $100-\mathrm{AB}$ & 5 & 5 & 3 & \\
\hline
\end{tabular}

Fonte: Autores. 


\section{Resultados e discussões}

\subsection{Desempenho mecânico}

A Figura 6 apresenta a resistência à compressão axial das argamassas testadas. O gráfico foi obtido a partir dos valores descritos na Tabela 9.

Analisando-se comparativamente os resultados da Figura 6, verifica-se que as argamassas com areia de britagem (50$\mathrm{AB}$ e 100-AB) tiveram resultados de resistência à compressão axial superiores (20,9\% e 30,9\%, respectivamente) aos da argamassa com areia natural, e que estas já aos 7 dias de cura apresentaram resistência superior a encontrada na argamassa referência. Além disto, os resultados mostram que nas argamassas com areia granítica o aumento da resistência à compressão axial é proporcional a quantidade de areia inserida.

A justificativa para tais fatos, possivelmente, está no grão da areia granítica que, além de anguloso, possui irregularidade e poros superficiais que podem ter aumentado a ancoragem com a matriz de cimento. Corroborando com os resultados dessa pesquisa, tem-se os estudos feitos pelos (Tokarski, 2017), (Karzmierczac, Rosa \& Arnold, 2016) e (Guacelli, 2011) que, também, identificaram que as areias de britagem pela sua forma angulosa geram maior resistência mecânica.

Figura 6 - Análise comparativa da resistência à compressão axial.

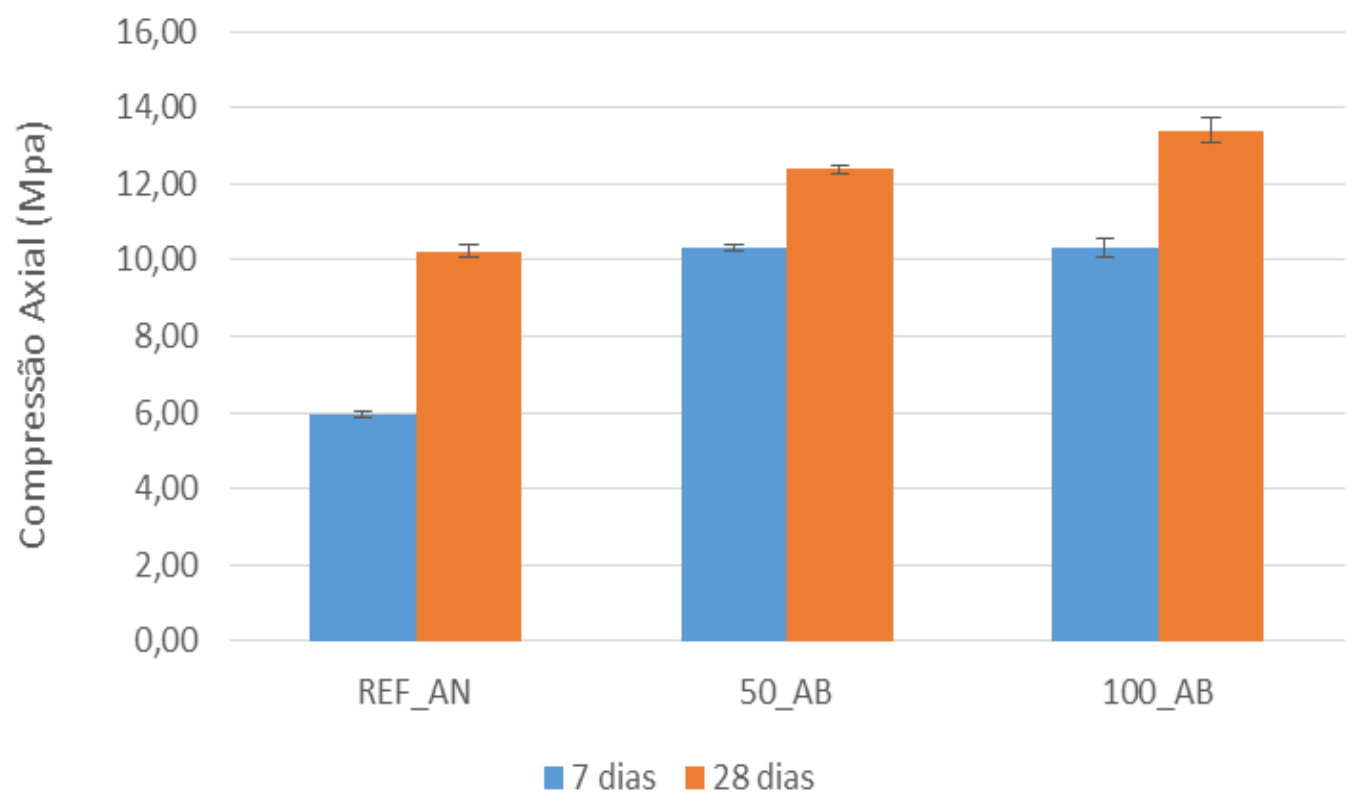

Fonte: Autores. 
Tabela 9 - Resultados de resistência à compressão axial (MPa).

\begin{tabular}{|c|c|c|c|c|c|c|}
\hline \multirow{2}{*}{ Traço } & \multicolumn{6}{|c|}{7 dias } \\
\hline & CP1 & $\mathrm{CP} 2$ & CP3 & $\mathrm{CP} 4$ & CP5 & Média \\
\hline REF_AN & 5,90 & 6,10 & 5,89 & 5,98 & 5,90 & 5,95 \\
\hline 100_AB & 10,60 & 10,45 & 10,20 & 9,98 & 10,36 & 10,32 \\
\hline 50_AB & 10,45 & 10,30 & 10,27 & 10,37 & 9,86 & 10,25 \\
\hline \multirow{2}{*}{ Traço } & \multicolumn{6}{|c|}{28 dias } \\
\hline & CP1 & $\mathrm{CP} 2$ & CP3 & $\mathrm{CP} 4$ & CP5 & Média \\
\hline REF_AN & 10,15 & 10,49 & 10,13 & 10,29 & 10,15 & 10,24 \\
\hline 100_AB & 13,78 & 13,59 & 13,26 & 12,97 & 13,47 & 13,41 \\
\hline 50_AB & 12,54 & 12,36 & 12,32 & 12,44 & 11,83 & 12,30 \\
\hline
\end{tabular}

Fonte: Autores.

Através da análise estatística ANOVA foi constatada a significância estatística das variáveis relacionadas, sendo elas o teor de substituição e idade na resistência à compressão axial. Na Tabela 10 estão apresentadas a análise de influência dos fatores e suas possíveis interações. Verifica-se que o teor de substituição não possuem efeito significativo sobre a resistência à compressão axial. Entretanto, existe influência significativa na idade. Além disto, é possível observar-se que o valor p é maior do que o nível de significância especificado $(\alpha=0,05)$. Portanto, a hipótese nula, que significa a igualdade entre as médias das resistências, é aceita.

Tabela 10 - Resultado de Análise de Variância - valor p - da resistência à compressão.

\begin{tabular}{cccccc}
\hline \multicolumn{5}{c}{ Tabela da ANOVA } \\
\hline Fator & G.L. & $\begin{array}{c}\text { Soma de } \\
\text { Quadrados }\end{array}$ & $\begin{array}{c}\text { Quadrado } \\
\text { Médio }\end{array}$ & Estat. F & p-valor \\
\hline Teor de substituição & 2 & 78,88236 & 19,72059 & 6,928441737 & 0,06532 \\
\hline $\begin{array}{c}\text { Idade } \\
\text { Idade }\end{array}$ & 1 & 1241,111976 & 620,555988 & 218,0201509 & $3,01 \mathrm{E}-28$ \\
\hline Reor de substituição x & 2 & 20,215224 & 2,526903 & 0,887777709 & 0,532279889 \\
\hline
\end{tabular}

Fonte: Autores.

A Figura 7 apresenta a resistência à tração na flexão a três pontos das argamassas testadas, em corpos de prova com 28 dias de cura. O gráfico foi obtido a partir dos valores descritos na Tabela 11.

Analisando-se a Figura 7, percebe-se que as argamassas com areia de britagem também obtiveram resultados de resistência à tração na flexão a três pontos superiores aos da argamassa com areia natural (REF-AN). Assim, como para o ensaio de resistência a compressão axial, a justificativa para estes resultados, possivelmente, está no grão da areia granítica que possui irregularidade e poros superficiais que podem ter aumentado a ancoragem com a matriz de cimento. 
Research, Society and Development, v. 10, n. 4, e39110414312, 2021

(CC BY 4.0) | ISSN 2525-3409 | DOI: http://dx.doi.org/10.33448/rsd-v10i4.14312

Figura 7 - Análise comparativa da resistência à tração na flexão a três pontos.

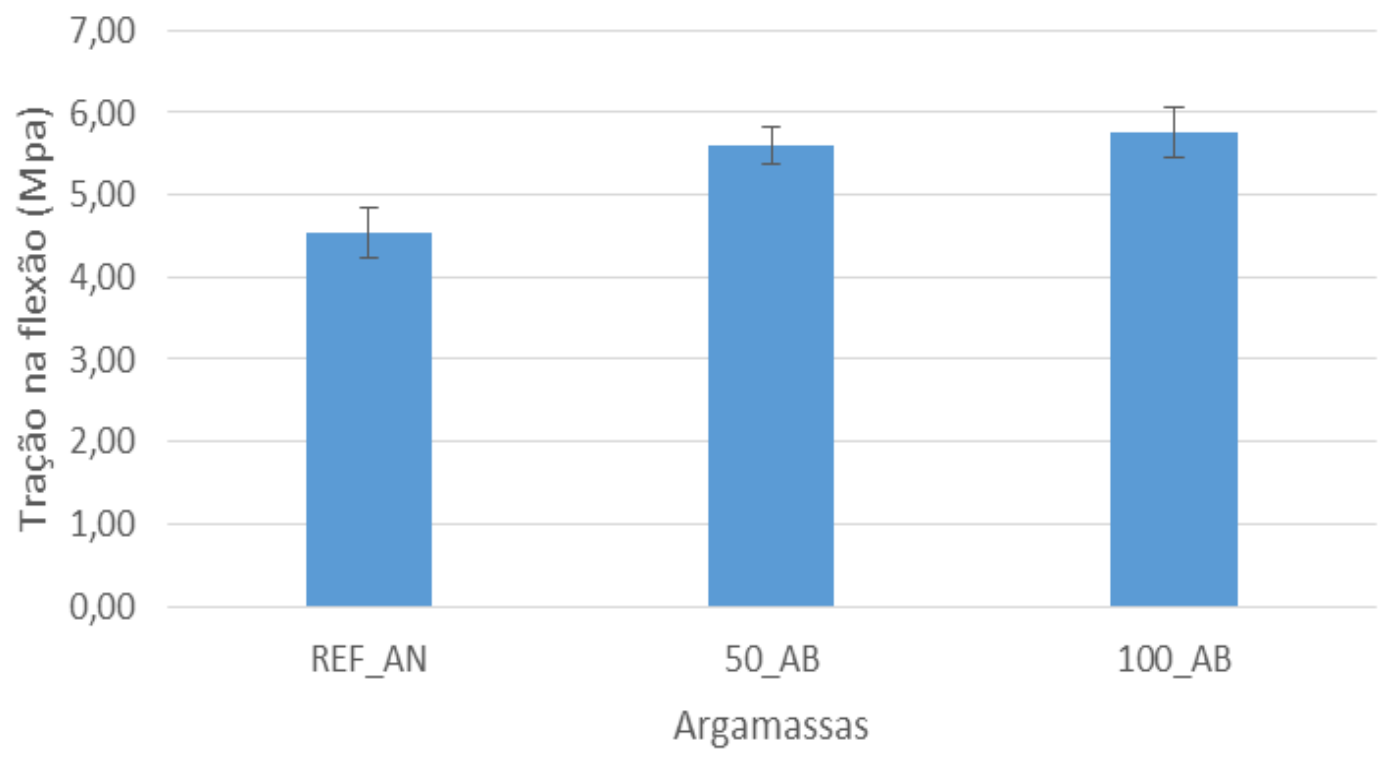

Fonte: Autores.

Tabela 11 - Resultados de resistência à tração na flexão a três pontos (MPa).

\begin{tabular}{c|c|c|c|c|c|c}
\hline \multirow{2}{*}{ Traço } & \multicolumn{7}{|c}{28 dias } \\
\cline { 2 - 7 } & CP1 & CP2 & CP3 & CP4 & CP5 & Média \\
\hline REF_AN & 4,20 & 4,56 & 4,90 & 4,80 & 4,24 & $\mathbf{4 , 5 4}$ \\
\hline 100_AB & 5,90 & 6,10 & 5,40 & 5,46 & 5,90 & $\mathbf{5 , 7 5}$ \\
\hline 50_AB & 5,80 & 5,78 & 5,70 & 5,40 & 5,34 & $\mathbf{5 , 6 0}$ \\
\hline
\end{tabular}

Fonte: Autores.

Através da análise estatística ANOVA foi constatada a significância estatística da variável Teor de Substituição na resistência à flexão. Na Tabela 12 está apresentada a análise de influência dos fatores, onde pode ser verificado que o teor de substituição possui efeito significativo sobre a resistência à flexão, indicado pelo p-fator de $0,08532 \%$ superior à $5 \%$. Pode-se concluir, com base nas análises de variância, que a hipótese de as médias serem iguais foi aceita, e que os efeitos da relação teor de substituição não são significantes ao nível de confiança de $95 \%$.

Tabela 12 - Resultado de Análise de Variância - valor p - da resistência à flexão.

\begin{tabular}{|c|c|c|c|c|c|}
\hline \multicolumn{6}{|c|}{ Tabela da ANOVA } \\
\hline & G.L. & Soma de Quadrados & Quadrado Médio & Estat. F & p-valor \\
\hline $\begin{array}{c}\text { Teor de } \\
\text { substituição }\end{array}$ & 2 & 3,8088 & 0,9522 & 7,841339555 & 0,08532 \\
\hline Resíduos & 10 & 1,214333333 & 0,121433333 & & \\
\hline
\end{tabular}




\subsection{Desempenho físico:}

A Figura 8 mostra a absorção por capilaridade das três diferentes argamassas. Os valores apresentados no gráfico da Figura 8 representam a média dos valores de absorção por capilaridade apresentados na Tabela 13.

Analisando-se o gráfico da Figura 8 é possível identificar a tendência de crescimento da absorção por capilaridade nos três traços de argamassa, sendo o traço com areia natural o de menor absorção capilar.

Percebe-se, também, que a argamassa com substituição total (100\%) da areia natural por areia granítica foi a que apresentou os maiores teores de absorção e que, na análise comparativa entre as argamassas com 50\% e 100\% de areia granítica, identificou-se que a menor quantidade de substituição resultou em uma argamassa com menores teores de absorção capilar, sendo estes próximos aos da argamassa com areia natural.

A justificativa para a maior absorção capilar das argamassas com areia granítica, possivelmente, está vinculada a forma angulosa dos grãos, que propicia um empacotamento com maior índice de vazios, e a presença de poros superficiais identificados no ensaio de teor de absorção de água dos grãos.

Quanto a redução de absorção de água na argamassa $50-\mathrm{AB}$, a justificativa para este resultado está, possivelmente, na presença dos dois tipos de agregado, a areia natural com esfericidade e a areia granítica com angulosidade, que possibilitaram um empacotamento com redução do índice de vazios.

Figura 8 - Análise comparativa da absorção por capilaridade das três argamassas.

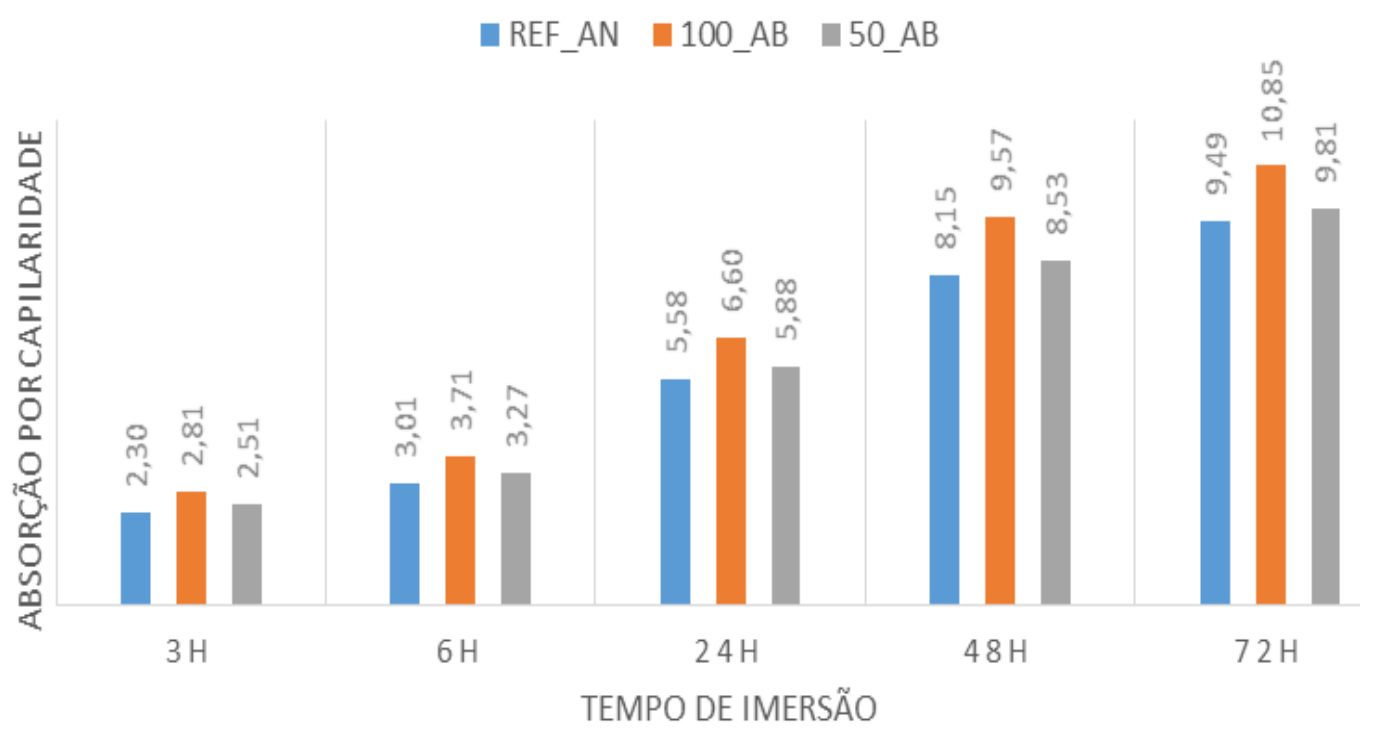

Fonte: Autores. 
Tabela 13 - Absorção por capilaridade.

\begin{tabular}{|c|c|c|c|c|c|c|}
\hline \multirow{2}{*}{ Traço } & \multicolumn{6}{|c|}{3 horas $\left(\mathrm{g} / \mathrm{cm}^{2}\right)$} \\
\hline & CP1 & $\mathrm{CP} 2$ & CP3 & $\mathrm{CP} 4$ & CP5 & Média \\
\hline REF_AN & 2,35 & 2,47 & 2,84 & 1,93 & 1,89 & 2,30 \\
\hline 100_AB & 2,94 & 2,96 & 3,55 & 2,32 & 2,27 & 2,81 \\
\hline \multirow[t]{3}{*}{ 50_AB } & 2,43 & 2,46 & 2,50 & 2,61 & 2,57 & 2,51 \\
\hline & \multicolumn{6}{|c|}{6 horas $\left(\mathrm{g} / \mathrm{cm}^{2}\right)$} \\
\hline & CP1 & $\mathrm{CP} 2$ & CP3 & $\mathrm{CP} 4$ & CP5 & Média \\
\hline REF_AN & 3,06 & 3,26 & 3,72 & 2,59 & 2,44 & 3,01 \\
\hline 100_AB & 3,88 & 3,91 & 4,69 & 3,06 & 2,99 & 3,71 \\
\hline \multirow[t]{3}{*}{ 50_AB } & 3,16 & 3,20 & 3,25 & 3,39 & 3,34 & 3,27 \\
\hline & \multicolumn{6}{|c|}{24 horas $\left(\mathrm{g} / \mathrm{cm}^{2}\right)$} \\
\hline & $\mathrm{CP} 1$ & $\mathrm{CP} 2$ & CP3 & $\mathrm{CP} 4$ & CP5 & Média \\
\hline REF_AN & 5,62 & 6,06 & 6,99 & 4,71 & 4,51 & 5,58 \\
\hline 100_AB & 7,10 & 6,34 & 8,43 & 5,44 & 5,69 & 6,60 \\
\hline \multirow[t]{3}{*}{ 50_AB } & 5,69 & 5,76 & 5,85 & 6,11 & 6,01 & 5,88 \\
\hline & \multicolumn{6}{|c|}{48 horas $\left(\mathrm{g} / \mathrm{cm}^{2}\right)$} \\
\hline & $\mathrm{CP} 1$ & $\mathrm{CP} 2$ & $\mathrm{CP} 3$ & $\mathrm{CP} 4$ & CP5 & Média \\
\hline REF_AN & 8,21 & 8,85 & 10,21 & 6,87 & 6,59 & 8,15 \\
\hline 100_AB & 10,29 & 9,19 & 12,23 & 7,89 & 8,25 & 9,57 \\
\hline \multirow[t]{3}{*}{ 50_AB } & 8,24 & 8,35 & 8,48 & 8,86 & 8,72 & 8,53 \\
\hline & \multicolumn{6}{|c|}{72 horas $\left(\mathrm{g} / \mathrm{cm}^{2}\right)$} \\
\hline & CP1 & $\mathrm{CP} 2$ & CP3 & CP4 & CP5 & Média \\
\hline REF_AN & 9,52 & 10,36 & 11,92 & 7,90 & 7,76 & 9,49 \\
\hline 100_AB & 11,73 & 10,75 & 13,94 & 8,68 & 9,16 & 10,85 \\
\hline 50_AB & 9,48 & 9,60 & 9,75 & 10,18 & 10,03 & 9,81 \\
\hline
\end{tabular}

Fonte: Autores.

\section{Conclusões}

Considerando os resultados obtidos, é possível inferir que a morfologia dos grãos da areia granítica apresenta formato anguloso e superfície irregular.

O ensaio de absorção de água das areias utilizadas mostrou que os grãos de areia granítica apresentam absorção duas vezes maior que a dos grãos de areia natural.

O alto teor de absorção de água das areias graníticas permiti concluir que estas possuem porosidade superficial.

A areia de britagem de origem granítica necessita de maior quantidade de água para obtenção de uma argamassa com consistência e trabalhabilidade adequadas.

As argamassas com areia de britagem de origem granítica apresentam maior absorção por capilaridade quando comparadas com a argamassa com areia natural, indicando possuírem estas maior índice de vazios que, possivelmente, se formaram devido a porosidade natural e o formato anguloso dos grãos. 
No tocante a resistência mecânica, quer seja na compressão axial ou na tração à flexão a três pontos, as argamassas com areia de britagem apresentaram maiores valores quando comparadas com a argamassas com areia natural.

O traço com $100 \%$ de substituição de areia natural por areia de britagem granítica foi o que efetivamente apresentou os maiores ganhos de resistência mecânica, no entanto segundo a análise estatística ANOVA a substituição em 50\% também seria efetiva.

Embora os resultados sejam satisfatórios, principalmente para os ensaios de resistências, deve-se atentar ao fato de que o alto índice absorção por capilaridade não é indicado para argamassas de revestimento.

Para trabalhos futuros sugere-se realizar ensaios de índice de vazios, aderência, análise de retração e fissuração, reologia das argamassas de areia de britagem granítica, ensaio com peneiras de séries intermediárias e aplicação das argamassas graníticas em um protótipo.

\section{Referências}

Ambrozewicz, P. H. L. Materiais de construção: normas, especificações, aplicações e ensaio de laboratório. Pini, 459 p.

Arnold, D. C. M. Análise da influência da forma dos grãos nas propriedades das argamassas. 145.

Associação brasileira de normas técnicas. Agregado miúdo - Determinação de massa específica e massa específica aparente. NBR NM 52 . 6 p.

Associação brasileira de normas técnicas. Agregado miúdo - Determinação da absorção de água. NBR NM 30.6 p.

Associação brasileira de normas técnicas. Agregados - Determinação da composição granulométrica. NBR NM 2486 p.

Associação brasileira de normas técnicas. Argamassa e concreto endurecidos - Determinação da absorção de água, índice de vazios e massa específica. NR $9778.4 \mathrm{p}$.

Associação brasileira de normas técnicas. Argamassa e concreto endurecidos - Determinação da absorção de água por capilaridade. NBR 9779. 3 p.

Associação brasileira de normas técnicas. Argamassa para assentamento e revestimento de paredes e tetos - Determinação da resistência à tração na flexão e à compressão. NBR $13279.9 \mathrm{p}$.

Associação brasileira de normas técnicas. Argamassa para assentamento e revestimento de paredes e tetos - Preparo da mistura e determinação do índice de consistência. NBR 13276. 2 p.

Associação brasileira de normas técnicas. Argamassa para assentamento e revestimento de paredes e tetos - Requisitos. NBR 13281.7 p.

Associação brasileira de normas técnicas. Determinação da resistência à compressão de corpos de provas cilíndricos. NBR 7215 . 8 p.

Associação brasileira de normas técnicas. Execução de revestimento de paredes e tetos de argamassas inorgânicas - Procedimento. NBR 7200. 13p.

Associação brasileira de normas técnicas. Revestimento de paredes e tetos de argamassas inorgânicas - Especificação. NBR 13749. 8 p.

Associação brasileira de normas técnicas. Revestimento de paredes e tetos de argamassas inorgânicas - Terminologia. NBR 13529.13 p.

Azevedo, A. R. G. et al. Effect of granite residue incorporation on the behavior of mortars. Materials, 12(9)

Bederina, M. et al. Effect of partial and total replacement of siliceous river sand with limestone crushed sand on the durability of mortars exposed to chemical solutions. Construction and Building Materials, 47, 146-158.

Callister J. R., Willian, R., \& David G. Ciência e engenharia de materiais: uma introdução. (8a ed.), LTC, 817p.

Caraseck, H. Argamassas. In: Instituo Brasileiro de Concreto. Livro de Materiais de Construção Civil, 2007

Cardoso, F. Método de formulação de argamassas de revestimento baseado em distribuição granulométrica e comportamento reológico. 138p. Tese de Doutorado - Departamento de Engenharia de Construção Civil, Escola Politécnica da Universidade Federal de São Paulo.

Cepuritis, R. et al. Comparison of 2-D and 3-D shape analysis of concrete aggregate fines from VSI crushing. Powder Technology, 309, 110-125.

Cepuritis, R., Jacobsen, S., \& Onnela, T. Sand production with VSI crushing and air classification: Optimising fines grading for concrete production with micro-proportioning. Minerals Engineering, 78, 1-14.

Cepuritis, R., Jacobsen, S., \& Onnela, T. Sand production with VSI crushing and air classification: Optimising fines grading for concrete production with micro-proportioning. Minerals Engineering, 78, 1-14.

Cordeiro, G. C., de Alvarenga, L. M. S. C., \& Rocha, C. A. A. Rheological and mechanical properties of concrete containing crushed granite fine aggregate. Construction and Building Materials, 111, 766-773. 
Farias e Palmeira. Agregados para a Construção Civil. In: Instituo Brasileiro de Concreto. Livro de Materiais de Construção Civil.

Fiorito, Antonio J. S. I. Manual de argamassas e revestimentos: Estudos e Procedimentos de Execução. (2a ed.), Pini Ltda, 232p.

Gao, Y., Schutter, G., \& Ye, G. Micro- and meso-scale pore structure in mortar in relation to aggregate content. Cement and Concrete Research, 52, 149-160.

Guacelli, P. A. G. Substituição de areia natural por areia de britagem de rochas basálticas para argamassas de revestimento. p. 166.

Han, D. et al. Critical Grain Size of Fine Aggregates in the View of the Rheology of Mortar. International Journal of Concrete Structures and Materials, 11(4), 627-635.

Kalagri, A., Karatasios, I., \& Kilikoglou, V. The effect of aggregate size and type of binder on microstructure and mechanical properties of NHL mortars. Construction and Building Materials, 53, 467-474, 2014.

Kazmierczak, C. de S., Rosa, M., \& Arnold, D. C. M. Influência da adição de filer de areia de britagem nas propriedades de argamassas de revestimento. Ambiente Construído, 16(2), 7-19.

Kockal, N. U. Investigation about the effect of different fine aggregates on physical, mechanical and thermal properties of mortars. Construction and Building Materials, 124, 816-825.

Kwan, A. K. H., Wong, V., \& Fung, W. W. S. A 3-parameter packing density model for angular rock aggregate particles. Powder Technology, $274,154-162$.

Lagerblad, B., Gram, H. E., \& Westerholm, M. Evaluation of the quality of fine materials and filler from crushed rocks in concrete production. Construction and Building Materials, 67, 121-126.

Neville, A. M., \& Brooks, J. J. Tecnologia do Concreto. (2a.ed.). Bookman, 448 p.

Rajan, B., \& Singh, D. Understanding influence of crushers on shape characteristics of fine aggregates based on digital image and conventional techniques. Construction and Building Materials, 150, 833-843.

Recena, Fernando Antonio Piazza. Conhecendo Argamassa. (2a ed.), EDIPUCRS, 188 p.

Santos, A. R. et al. Microstructure as a critical factor of cement mortars' behaviour: The effect of aggregates' properties. Cement and Concrete Composites, 111.

Srivastava, A., \& Singh, S. K. Utilization of alternative sand for preparation of sustainable mortar: A review. Journal of Cleaner Production, 253, 119706, 2020 .

Stolz, C. M., \& Masuero, A. B. Influence of grains distribution on the rheological behavior of mortars. Construction and Building Materials, 177, 261-271, 2018

Tokarski, R. B. Comportamento da areia de britagem de rocha calcárica na argamassa de revestimento p.157. 2017.

Zhang, W., Zakaria, M., \& Hama, Y. Influence of aggregate materials characteristics on the drying shrinkage properties of mortar and concrete. Construction and Building Materials, 49, 500-510, 2013. 